\title{
Standards Framework for Intelligent Manufacturing Systems Supply Chain
}

\author{
Ricardo Jardim-Goncalves ${ }^{1}$, Carlos Agostinho², João Sarraipa², \\ Amparo Roca de Togores 3 , Maria José Nuñez ${ }^{3}$ and Hervé Panetto 4 \\ ${ }^{1}$ DEE/FCT - Universidade Nova de Lisboa Caparica \\ ${ }^{2}$ UNINOVA-GRIS - Centre of Technology and Systems, Caparica \\ ${ }^{3}$ AIDIMA - Asociación de Investigación y Desarrollo \\ en la Industria del Mueble y Afines, Valencia, \\ ${ }^{4}$ CRAN, Nancy-University, CNRS, Nancy, \\ 1,2Portugal \\ ${ }^{3}$ Spain \\ ${ }^{4}$ France
}

\section{Introduction}

The global market is striving to increase competitiveness among organizations and networks. Nowadays, management of supply chains does not only consider business processes in the traditional value chain, but also processes that penetrate networks of organisations. Indeed, the formation of cooperation and collaboration partnerships between several small organizations can be, in multiple cases, more efficient by comparison with big companies (Rudberg et al., 2002). This way, the research on supply chain management has turned from an intra-enterprise focus towards an inter-enterprise focus with companies looking for enhanced interoperability between computer systems and applications.

Supply chain networks are characterized by different structures such as, business processes and technological, organizational, topological, informational, and financial structures. All are interrelated but following their own dynamics. Thus, in order to ensure a high responsiveness level, the supply chain plans must be formed robustly and extremely quickly in relation to all the structures (Gupta \& Maranas, 2003). In fact, with regards to supply chain in the advent of globalization, one of the difficulties enterprises are facing is the lack of interoperability of systems and software applications to manage and orchestrate the different structures involved (Farinha et al., 2007; Jardim-Goncalves et al. 2006a; Panetto et al., 2006). The increasing need for cooperation and collaboration together with the rapid advances in information and communication technology (ICT) have brought supply chain planning into the forefront of the business practices of most manufacturing and service organizations (Gupta \& Maranas, 2003). Moreover, there has been a growing interest and research in e-business solutions to facilitate information sharing between organisations in the supply chain network.

However, despite enterprise networks and partnerships are desirable, the automation of processes still suffer some problems mainly in integrating Product Life Cycle (PLC) phases, 
since manufacturers, distributors, designers, retailers, warehouses, often use proprietary solutions which are, typically, not interoperable with another (Jardim-Goncalves et al., 2007a). The exchange of information and documents between partners often cannot be executed automatically or in electronic format as desirable which creates inefficiencies and unexpected cost increase that might challenge the advantages of the network when not addressed (Brunnermeier \& Martin, 1999). With this diffuse range of systems, industry has had its development of trading and supply partnerships restrained, e.g. inhibiting the shared fabrication of products. These barriers are real factors that stop innovation and development.

Therefore, standardization rapidly became an evident priority, and several dedicated reference models (e.g. ISO 10303, also known as STEP, the standard for the exchange of product model data) covering many industrial areas and related application activities, from design phase to production and commercialization, have been developed enabling industrial sectors to exchange information based on common models (Jardim-Goncalves et al., 2006a). STEP Application Protocols have been widely used in industrial environments, to support systems interoperability through the exchange of product data in manufacturing domains. Using them, designers and manufacturers will get a considerable advantage over those that don't (Agostinho et al., 2009). Sending and receiving e-commerce documents in standardised format may get easier access to new markets and facilitate the management of product data through PLC phases, reducing administration costs when handling quotations, orders, as well as the opportunity to have e-catalogues, product customization, user-centric design, etc. Nevertheless, alone, this kind of data representation standards does not solve semantic problems (Jardim-Goncalves et al. 2011; Sarraipa et al., 2009a). Moreover, industrial standards as STEP, often use technologies unfamiliar to most application developers or too expensive for SME-based industries which cannot spend large amounts of time and effort trying to implement standard recommendations and training the employees (Jardim-Goncalves et al., 2006b \& 2007b).

Indeed, these kinds of organizations are much liable to use more user-friendly and supported technologies, such as Extensible Markup Language (XML) or Unified Modeling Language (UML). Their simplicity and the large availability of implementing tools make them popular and very well accepted. Therefore, a possible solution to facilitate the use of STEP and promote its adoption, would be to use standard-based platforms capable of applying rigorously defined transformation rules (i.e. morphims) to STEP models, and supplying them to the industrial communities in different languages. This would allow reusing existing expertise and extending STEP capabilities in complementary application domains, like advanced modelling tools, knowledge management and the emergent semantic web technologies (Agostinho et al., 2007a).

More recently, the development of ontologies is promising to provide companies with capabilities to solve semantic issues. Thus, each company is struggling to develop competencies at this ontological level, but inevitably different perspectives will lead to different final results, and achieving different ontologies in the same business domain is the reality. One possible solution is to have a common ontology for a specific domain that all the networked enterprises use in their business. Although, to force manufacturers or suppliers to adopt a specific ontology as reference is not an easy task, since each enterprise does not foresee any outcomes by changing their knowledge. An advantageous solution would be to let them to keep their terminology and classification in use, and adopt a reference ontology, 
which will complement the data standard and become the organization knowledge frontend, enabling inter-enterprises communications sharing the same terminology and semantics (Sarraipa et al., 2009b).

Together with standards development, interoperability solutions have enabled a smooth progress of supply chain systems to a next phase, where flexibility, intelligence and reconfiguration should be reached. The 'intelligence' concept becomes more relevant because of the need to maintain effective and efficient operations with minimum downtime under conditions of uncertainty (Molina et al., 2005). Intelligence is taken to mean advanced and efficient manufacturing technologies, management and procedures. Therefore, the solution explored in this chapter to reach such intelligence is exploring the use of data morphims for standards integration and formal ontologies as a way of specifying contentspecific agreements for the sharing and reuse of knowledge among software entities (Gruber, 1995).

\section{Furniture sector problems and motivations for an intelligent supply chain}

Based on the number of people it employs, the furniture industry is the largest manufacturing sector in the world, involving mostly Small and Medium Enterprises (SMEs) (Gaston \& Kozak, 2001; Roca de Togores \& Agostinho, 2008). To keep its competitiveness, Europe needs to accomplish rapidly the requirements in the digital global marketplace, and push promptly SME-based industry to adopt seamless electronic business services in networked enterprise environments using of modern ICT and standards among all agents involved in the furniture product life cycle (Fan \& Filos, 1999; Jardim-Goncalves et al., 2006a \& 2008).

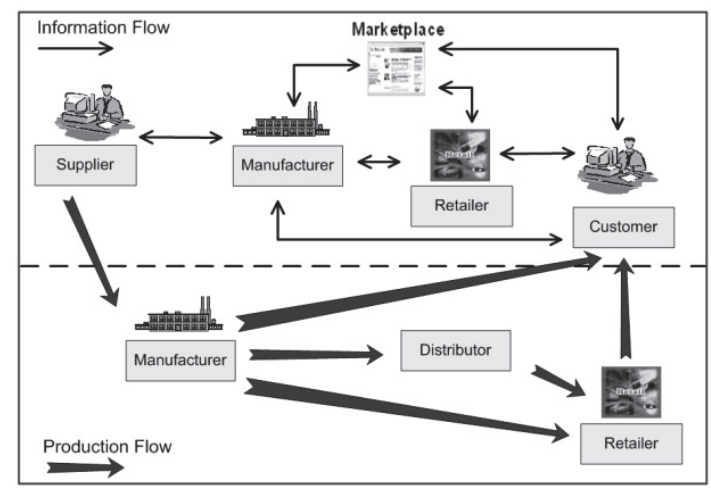

Fig. 1. Furniture supply chain flows (Jardim-Goncalves et al., 2007b)

The furniture supply chain is an end-to-end process required to procure, produce and deliver furniture-related products and services to customers. During this process and, based on the customer's order, raw materials, supplies and components are modified into finished products and then distributed to the customers. Between the different players in the supply chain, there are three main types of flow, namely production and information (represented in Fig. 1) and financial. The first usually involves moving goods while the information flow involves exchanging product data, electronic catalogues and orders, with the information seamlessly exchanged between parties, giving the customer better choices, by offering them a degree of power in customising their own particular product choices. 
This way, the problem of data exchange to support the PLC phases of furniture product life cycle when doing business between manufacturers, retailers, suppliers, and customers is well understood (European Comission [EC], 2008a). In fact, the furniture community considers this problem as a major inhibitor of electronic businesses, and although identified as a problem for the furniture industry, there is a global concern in the SME-based industrial sectors.

Historically, companies have managed information flows in a number of ways, including telephone calls, letters, telex, faxes, and electronic data interchange (EDI) managed by a number of proprietary systems. More recently, the availability of reliable high-speed internet connections has become widespread and the cost of implementing technological solutions has dropped. Consequently, companies have begun to make better use of ICT to automate critical business communications. Indeed, furniture industry has become increasingly international, with retailers buying goods from manufacturers all over Europe. Similarly, manufacturers source raw materials from suppliers worldwide (Roca de Togores \& Agostinho, 2008).

Product data standards (where they exist) differ across national boundaries, so the development of international product data standards extends business opportunities across the global supply chain. Many separate companies involved in the design, manufacture, sale and distribution of furniture, are requiring the sharing and exchange of huge volumes of information. For this reason, the funStep community (www.funStep.org) was setup in the late 90s with the support of European Commission, for implementing an European research strategy for better interoperability in organizations operating in networked environments.

The main objective of the funStep's initiative is to research, develop and demonstrate in industrial environments, an open standards-based framework that supports the complete product life cycle in the furniture supply chain. This should be done adopting secure electronic services, and networked enterprise practices between other organizations, throughout agents, products, and services at 2 levels (Jardim-Goncalves et al., 2008):

- Interoperability among business user applications, and

- Interoperability among electronic commerce platforms.

The SMART-fm and INNOVAFUN 1 projects were two of the funStep driven projects that conducted to R\&D initiatives pushing forward intelligent systems able to solve interoperability problems. SMART-fm objective was defined to improve effectiveness across the entire furniture manufacturing sector by adoption of a reference method of classification and intelligent information sharing. A major achievement of the project was to reach the enquiry stage for the STEP Application Protocol 236 standard submission, which was approved by unanimous consensus on that time. INNOVAFUN followed to bridge the gap between industry and research developments. It defined use-cases for the standard implementation and detailed a toolbox of intelligent services to enable SME's innovation. It also contributed for the identification of key open research questions, together with the findings and discussions in the international Enterprise Interoperability (EI) research community, that are guiding research nowadays (EC, 2008b \& 2010; Jardim-Goncalves et al., 2010):

- Why is there so much effort wasted on the development of dedicated technical solutions for interoperability problems? How can this be reduced?

${ }^{1}$ SMART-fm IMS (IST-2001-52224) and INNOVAFUN (INNOVA-031139) 
- How can we predict and guarantee the long-term knowledge and behaviour of interoperability in engineering and manufacturing systems?

- How do we reduce complexity in EI and provide "Interoperability as a Service" (IaaS)? Along these lines, can interoperability services be used as "plug-and-play" mechanisms independently of the EI level for which they are designed (higher levels such as business, or lower ones such as technical applications)?

\section{STEP paradigm and ISO 10303-AP236, the funStep Standard}

Standards play a crucial role in the definition of market conditions in many industrial sectors and not only in high-technology sectors. Their use is accelerating technological and organisational change and thus improving innovation processes. They play a major role in promoting innovative products and services, by providing stable references for the development of new innovative solutions and creating large scale markets. In addition, nontechnological standards help shaping new organisational forms and business models and contribute to raising the quality of services and to the efficiency of business processes (Roca de Togores \& Agostinho, 2008).

The International Organization for Standardization (ISO) has been pushing forward the development of standards and models. Efforts like STEP have tried to deal with integration and interoperability issues, thus contributing to the reduction of transaction costs involved in the development and application of (new) technologies and of generating positive network externalities by reaching economies of scale. There is evidence to suggest that well implemented standards may contribute to the innovation process and therefore to economic growth (EC, 2008a). However, information must be neutral and unbiased in order to be credible.

STEP is a family of standards for the computer-interpretable representation of product information and for the exchange of product data under the manufacturing domain. It defines a framework which provides neutral mechanisms that are capable of describing products throughout their life cycle. From modelling, through data formats, to industrial data definition and conformance methodologies, STEP is widely used in Computer Aided Design (CAD) and Product Data Management (PDM) systems. It is nowadays adopted by major industrial companies in the world. Among them, are the automotive, aircraft, shipbuilding, furniture, building and construction, gas and oil industries, which use STEP for integration of manufacturing systems, some with significant savings (White et al. 2004). STEP Application protocols (APs) are information models that capture the semantics of a specific industrial requirement and provide standardized structures, within which, data values can be understood by a computer implementation. This way, ISO 10303-236 (ISO TC184/SC4, 2006), also known as AP236 or the funStep standard, is the part of STEP that defines a formalized structure for catalogue and product data under industrial domains of the furniture sector. AP236 is focused on product definition of kitchen and domestic furniture, extensible to cover the whole furniture domain (e.g., bathroom, office, etc.). It is a foundation for data exchange in the furniture industry so that all the software involved in the design, manufacturing and sale of a product, understands the same vocabulary.

\subsection{Modular design to enable reuse}

As illustrated in Fig.2 (left side), the AP236 standard is designed in order to optimize reutilization of existent standard models through modularization of components. Similar 

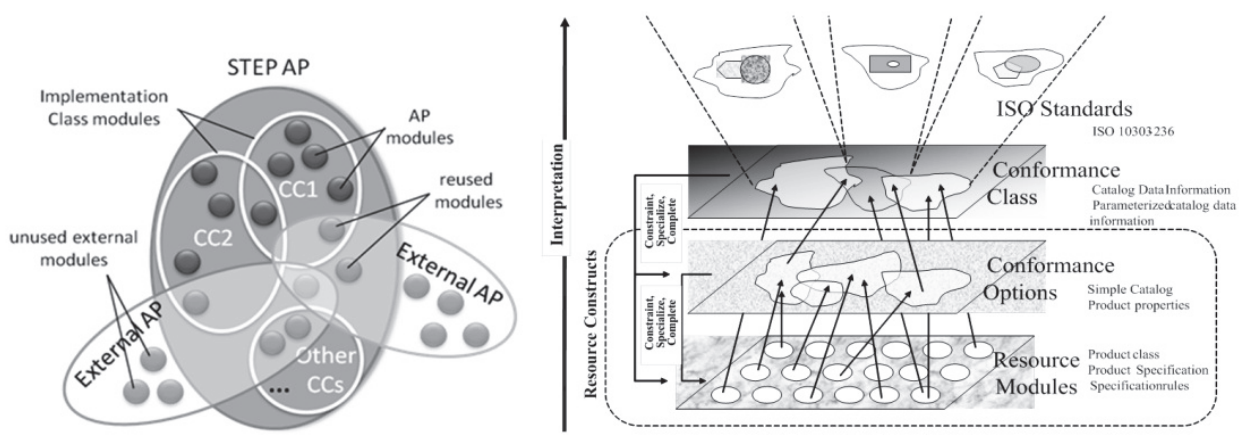

Fig. 2. Modular STEP AP and grouping into conformance options and classes

and common requirements have been identified from existent STEP APs, and subsets of these models (i.e. modules) were selected to be integrated as part of AP236 (Agostinho et al., 2009; Feeney, 2002; Jardim-Gonçalves et al., 2005). This characteristic enables a faster standard development process and guarantees a certain degree of cross-sectorial interoperability since some of the modules are the same. Product and interior designers, as other stakeholders, may now be part of multiple supply chains without greater concerns with interoperability issues since many other STEP industrial standards use some of the same resource models.

However, as illustrated on the right side of Fig.2 in addition to reutilization, modularization in AP236 also enables to define implementation/conformance classes (CCs) and options according to the stakeholder profiles. For example, in the furniture case, modules are grouped in six different implementation classes which allow different stakeholders to implement funStep at different levels of compliance namely2 (Fig. 3):

- Simplified catalogue (CC1), which is still subdivided in 6 smaller conformance options to enable targeted implementations of micro enterprises (INNOVAFUN, 2008);

- Catalogue data and product geometry representation (CC2);

- $\quad$ Parameterized catalogue (CC3);

- Interior decoration project (CC4);

- Parameterized catalogue data and product geometry representation (CC5);

- Full AP236 that encompasses the others (CC6).

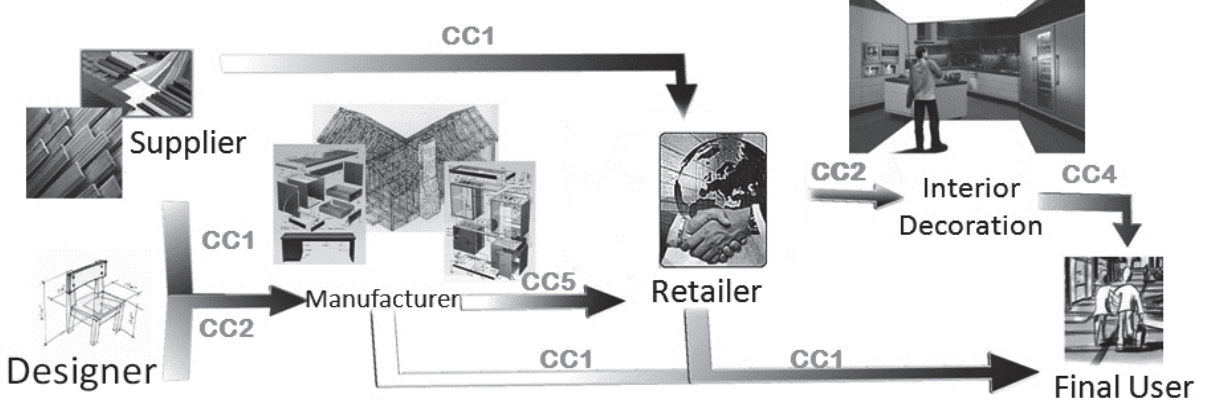

Fig. 3. funStep conformance classes needed in stakeholder relationships

${ }^{2}$ The enumerated names are simplified and do not correspond to the official AP236 CC names. Please refer to ISO TC184/SC4 (2006) for the formal designations. 


\subsection{Use case suite for the adoption and implementation of funStep standard}

The ideal scenario in the communication between two different furniture stakeholders is that both of them are fully compliant with the funStep standard for product data. However, if that is not possible, the stakeholder receiving the information should have the same or higher level of compliance than the sender. Considering the number of CCs implemented: it is possible to define three different levels of funStep compliance (Agostinho et al., 2009):

- Level 0, the stakeholder has no part of the standard adopted and interoperability is never guaranteed;

- Level 1, for the stakeholders that have adopted some CC modules of AP236. Here, in a typical data exchange scenario, interoperability is only assured if the CCs implemented are the same, or if the receiver stakeholder implementations encloses the sender's CCs;

- $\quad$ Level 2, for the stakeholders that have adopted full AP236, i.e. CC6.

At present most of the furniture companies have not yet adopted any part of the funStep standard and will be on level 0 of compliance. Also, as analysed by Agostinho et al. (2009), many are in different maturity stages of ICT adoption which conditions the way they can adopt and implement funStep:

- Maturity stage "Does not have an ICT Infrastructure". This is the case where no ICT equipment is used in the organization and all information is stored in paper format. In this case many design specifications are still being sent by fax to manufacturers;

- Maturity stage "Has an ICT Infrastructure, but is not focused for information exchange". This is the case common to the majority of SMEs, where companies have computers, internet connection but have no specialized system to enable creative design, e-commerce or any kind of information management (e.g. ERP);

- Maturity stage "Has an ICT Infrastructure for information exchange and management". This case reflects the situation of companies that have already invested in a system to enable e- business and PLC management. In this situation companies might already be adopting funStep (fully or partially), or may use proprietary formats not understandable by all, thus obstructing seamless interoperability.

Considering both the levels of funStep compliance and the ICT maturity in SME environments, the authors propose a methodology for the adoption and implementation of AP236 based on a set of 12 use cases which show the actions stakeholders should carry for a fast implementation of STEP standards, namely funStep. Table 1 guides the implementors on the order of UCs they should follow, to adopt certain parts of funStep and raise the level of compliance. This best practice methodology eliminates part of the complexity of implementing a STEP standard, i.e. where to start.

\subsection{An e-marketplace implementing AP236 for the supply chain information flow}

To better illustrate how the proposed use-case suite works, its best to follow an example: let's say that a furniture e-marketplace decides to implement the funStep standard to regulate his supply chain information flow as in Fig.1. Due to its business scope, the marketplace already uses an ICT system that enables to electronically receive furniture catalogues from different manufacturers, thus has an ICT Infrastructure for information exchange and management (highest ICT maturity level). However, it doesn't implement yet AP236 (level 0) and due to the heterogeneity of the information received, has trouble enlarging its business network. 


\begin{tabular}{|c|c|c|c|c|}
\hline ICT Maturity & $\begin{array}{l}\text { Complia } \\
\text { nce }\end{array}$ & & Steps (\#, name) & $\begin{array}{l}\text { Use- } \\
\text { case \# }\end{array}$ \\
\hline \multirow{5}{*}{$\begin{array}{l}\text { Does not have an ICT } \\
\text { Infrastructure }\end{array}$} & \multirow{5}{*}{ Level 0} & 1 & Uptake basic ICT & UC-01 \\
\hline & & 2 & Build data system based on funStep & UC-02 \\
\hline & & 3 & Implement system interfaces & UC-03 \\
\hline & & 4 & Populate data system & UC-04 \\
\hline & & 5 & Test the level of funStep compliance & UC-05 \\
\hline \multirow{4}{*}{$\begin{array}{l}\text { Has an ICT } \\
\text { Infrastructure, but is } \\
\text { not focused for } \\
\text { inform. exchange }\end{array}$} & \multirow{4}{*}{ Level 0} & 1 & Build data system based on funStep & UC-02 \\
\hline & & 2 & Implement system interfaces & UC-03 \\
\hline & & 3 & Migrate internal data to funStep system & UC-06 \\
\hline & & 4 & Test the level of funStep compliance & UC-05 \\
\hline \multirow{7}{*}{$\begin{array}{l}\text { Has an ICT } \\
\text { Infrastructure for } \\
\text { information } \\
\text { exchange and } \\
\text { management }\end{array}$} & \multirow{7}{*}{$\begin{array}{l}\text { Levels } 0, \\
\text { and } 1\end{array}$} & 1 & $\begin{array}{l}\text { Find requirements that the current system does } \\
\text { not answer }\end{array}$ & UC-07 \\
\hline & & 2 & $\begin{array}{l}\text { Analyse how funStep could answer the } \\
\text { requirements }\end{array}$ & UC-08 \\
\hline & & 3 & $\begin{array}{l}\text { Discover mapping from internal system to } \\
\text { funStep (if starts from level 0) }\end{array}$ & UC-09 \\
\hline & & 4 & $\begin{array}{l}\text { Implement functionalities / services to } \\
\text { transform internal data in funStep data and } \\
\text { vice-versa (if starts from level 0) }\end{array}$ & UC-10 \\
\hline & & 5 & Implement new parts of funStep (if required) & UC-11 \\
\hline & & 6 & $\begin{array}{l}\text { Implement system interfaces for the new parts } \\
\text { (if required) }\end{array}$ & UC-12 \\
\hline & & 7 & Test the level of funStep compliance & UC-05 \\
\hline
\end{tabular}

Table 1. Use-Case (UC) suite for the adoption of the funStep standards

Clearly the e-marketplace is suffering from an interoperability problem, and according to Fig. 2 would need the first conformance class (CC1) of the AP236 standard to be able to receive catalogue data from more manufacturers. However, if the marketplace, as a more technologically advanced form of retailer, already includes innovative product visualization functionalities and placement of furniture objects inside a room, would probably be interested in the implementation of CC2 and CC4 as well.

Following Table 1, the marketplace should start by finding and detailing the exact requirements that the current system does not answer (UC-07). Next, the second step relies on the profound analysis of the standard capabilities to see if and how it will solve the problem (UC-08), i.e. decide which conformance options and/or CCs to implement. The procedure continues with UC-09 defining morphims from internal system functionalities and structures to the standard constructs, UC-10, UC-11 and UC-12 for the implementation of the morphisms and new functionalities if required, until it reaches UC-05 where it is foreseen that the organization will check if its implementation has been successful and obtains a compliance level certificate. 
Due to space restrictions the full details of the use-case actions are not here detailed and can be found on INNOVAFUN (2007).

\section{Framework for the independency of STEP languages}

STEP data has traditionally been exchanged using ISO10303-21 (Part 21) (ISO TC184/SC4, 2002), an ASCII character-based syntax. Although it's sufficient for the task, it lacks extensibility, it's hard for humans to read, and it's interpretable only by systems supporting STEP. This is one of the drawbacks STEP faces regarding its use and adoption by a wider community, namely among SMEs. Another drawback is the fact that the STEP modelling language (used in all their APs), EXPRESS (ISO10303-11) (ISO TC184/SC4, 2004), is unfamiliar to most applications developers. Although it is a powerful language, it has been relatively unknown in the world of generic software modelling tools and software engineers (Subrahmanian et al. 2005). As opposed to other modelling technologies, such as UML or XSD, few software systems support EXPRESS (Agostinho et al., 2006 \& 2007a \& 2007b).

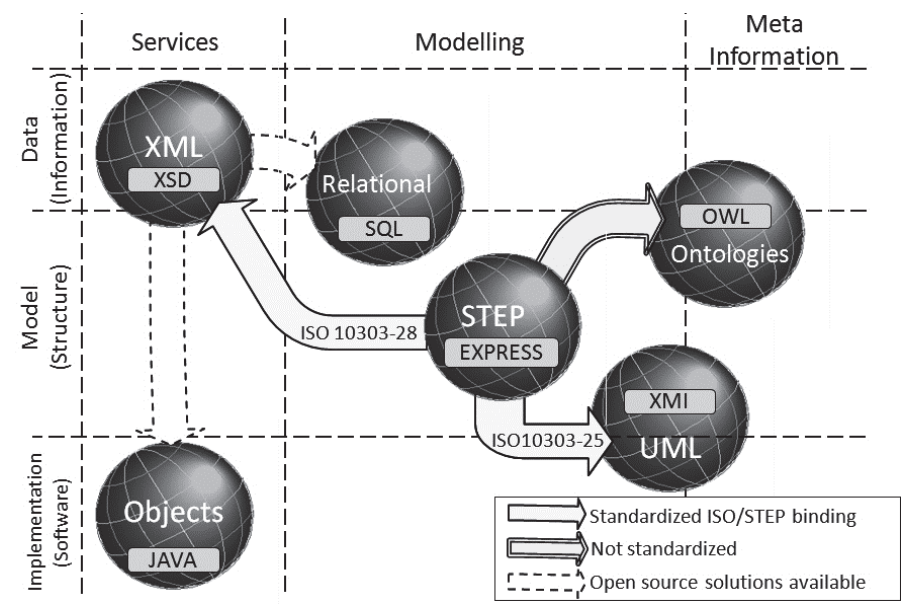

Fig. 4. Integration of STEP with other technologies

In summary, the STEP standard, despite being very powerful regarding the representation and the exchange of product data, is not very popular among the application developer's community. Therefore, and because of the massive adoption and deployment of other standard technologies, like XML and UML, the authors believe that the path to follow is to define morphisms from STEP to these standard technologies, leveraging the cemented knowledge gathered by STEP, with the popularity of the other standards (see Fig. 4). This harmonization among complementary technologies would become a powerful tool for lowering the barriers of STEP implementations and enable to widespread exchange and share of digital data.

Several international research projects, like the Athena IP and the InterOP NoE ${ }^{3}$, in addition to the funStep driven projects mentioned in section 2, have been supporting the development and validation of similar solutions that apply innovative concepts such as the Model Driven

${ }^{3}$ ATHENA IP (IST-507849) and InterOP NoE (IST-508011) 
Architectures (MDA), ontologies or Model Morphisms (MoMo) to solve real industrial interoperability scenarios (Agostinho et al. 2007a; Franconi, 2004; INTEROP, 2005; JardimGoncalves et al.,2007b; Kalfoglou \& Schorlemmer, 2003; Lubell et al., 2004; Sarraipa et al., 2010).

\subsection{Model Morphisms (MoMo)}

Morphism is an abstract concept drawn from mathematics for describing a structurepreserving map between two structures. It can be a function linking two objects or aggregations of objects in set theory; the relation between domain and co-domain in category theory; or the transformation operator between two vector spaces, in linear algebra (INTEROP, 2005). Recently, this concept as been gaining momentum applied to computer science, namely to systems interoperability where it specifies the relations (mapping, merging, transformation, etc) between two or more information model specifications (let $M$ be the set of all models). In this context, a MoMo describes a model operation.

\begin{tabular}{|c|c|c|}
\hline MoMo & Formalization & Classification \\
\hline $\begin{array}{l}\text { Mapping: } \\
\theta(A, B)\end{array}$ & $\forall A, B \in M: \theta(A, B) \subseteq \operatorname{Sub}(A) \times \operatorname{Sub}(B)$ & Non-altering \\
\hline $\begin{array}{l}\text { Transformation: } \\
\tau: A \times \theta \rightarrow B\end{array}$ & $\forall A, B \in M:$ if $\exists \theta(A, B)$ then $\tau(A, \theta)=B$ & Model altering \\
\hline $\begin{array}{l}\text { Merging: } \\
\lambda: A \times B \times \theta \rightarrow C\end{array}$ & $\begin{array}{c}\forall A, B, C \in M: \\
\text { if }(\exists \theta(A, C) \wedge \quad \exists \theta(B, C)) \text { then } \lambda(A, B, \theta)=C \\
\text { and } C \subseteq A \cup B\end{array}$ & Model altering \\
\hline
\end{tabular}

Table 2. Types of MoMo

INTEROP (2005) was the catalyst for the MoMo research applied to interoperability domains identifying two core classes of MoMo, i.e., non-altering and model altering morphisms. Since then the authors have been formalizing interoperability operations accordingly and classifying them within the morphism types specified in Table 2 (Agostinho et al., 2007a \& 2011):

- In the non-altering morphisms, given two models (source model $A$ and target model $B$ ), a mapping relationship is created relating each element of the source with a correspondent element in the target, leaving both models intact.

- In model altering morphisms, the source model is transformed using a function that applies a mapping to the source model and outputs the target model. Other relations, such as the merge operation, can also be classified as model altering morphisms since it is a transformation with two input models.

The integration of technologies envisaged in Fig. 4 targets model altering morphims, namely transformations where the source model $A$ is translated into a different modelling language in the target model $B$, thus accomplishing the harmonization of STEP with other more popular and less expensive technologies.

\subsubsection{EXPRESS to XSD transformation}

This function translates an EXPRESS schema to XML Schema (XSD) format according to the standardized mapping rules defined by Part 28 of STEP (ISO10303-28) (ISO TC184/SC4, 2007). Adopting the mathematical notation to define the morphism, let: 
a. $M E X P$ be the set of all models described by the EXPRESS language, $M E X P \subseteq M$;

b. $M X S D$ be the set of all XML models described in XSD, $M X S D \subseteq M$;

c. $\theta(M E X P, M X S D)$ the mapping defined ISO10303-28;

EXP2XSD is a transformation $\tau: A \times \theta \rightarrow B$, where $\forall A \in M E X P, \exists B \in M X S D: \tau(A, \theta)=B$. Its implementation is detailed in section 4.2.

\subsubsection{EXPRESS to XMI transformation}

This function translates an EXPRESS schema to XMI format of the Unified Modeling Language (UML) according to the standardized mapping rules defined by Part 25 of STEP (ISO10303-25) (ISO TC184/SC4, 2005). Adopting the mathematical notation to define the morphism, let:

a. $M E X P$ be the set of all models described by the EXPRESS language, $M E X P \subseteq M$;

b. $M X M I$ be the set of all UML models described in XMI, $M X M I \subseteq M$;

c. $\theta(M E X P, M X M I)$ the mapping defined ISO10303-25;

EXP2XMI is a transformation $\tau: A \times \theta \rightarrow B$, where $\forall A \in M E X P, \exists B \in M X M I: \tau(A, \theta)=B$. Its implementation is detailed in section 4.2 .

\subsubsection{EXPRESS to OWL transformation}

This function translates an EXPRESS schema to OWL format according to a set of customized mapping rules defined by the authors (Agostinho et al., 2007b). Adopting the mathematical notation to define the morphism, let:

a. $M E X P$ be the set of all models described by the EXPRESS language, $M E X P \subseteq M$;

b. $M O W L$ be the set of all OWL models, $M O W L \subseteq M$;

c. $\theta(M E X P, M O W L)$ the mapping defined by Agostinho et al. (2007b);

EXP2OWL is a transformation $\tau: A \times \theta \rightarrow B$, where $\forall A \in M E X P, \exists B \in M O W L: \tau(A, \theta)=B$. Its implementation is detailed in section 4.2.

\subsubsection{XSD to RDB and XSD to JAVA transformations}

As in the previous 3, these functions are also transformations, however, the input model is an XML Schema (XSD) and the outputs are in the form of relational database SQL scripts or object-oriented classes. These morphisms complete the framework of Fig 4 using mappings realized by open source solutions available that can be parameterized to produce the desired results, and enable developers to have access to STEP standards even at an implementable format. The formalization follows the same logic as before.

\subsection{MDA-based transformations for STEP models}

To accomplish the above EXPRESS-based morphims, a funStep research prototype, i.e. the UniSTEP-toolbox, as been developed applying the principles of the OMG MDA methodology ${ }^{4}$. MDA recommends handling of information at different meta-levels for integration purposes (Frankel, 2003; Jardim-Goncalves et al., 2006c). At that level, the effort to define valid transformation morphisms from the EXPRESS modelling language to others is heavily reduced since there is more information available about both the operand model languages (input and output). Hence, for the UniSTEP development, the OMG EXPRESS metamodel (Object Management Group [OMG], 2009) as been used specifying all the possible variations that a STEP data model can have.

${ }^{4}$ OMG Model Drivel Architectures (MDA). www.omg.org/mda/ 


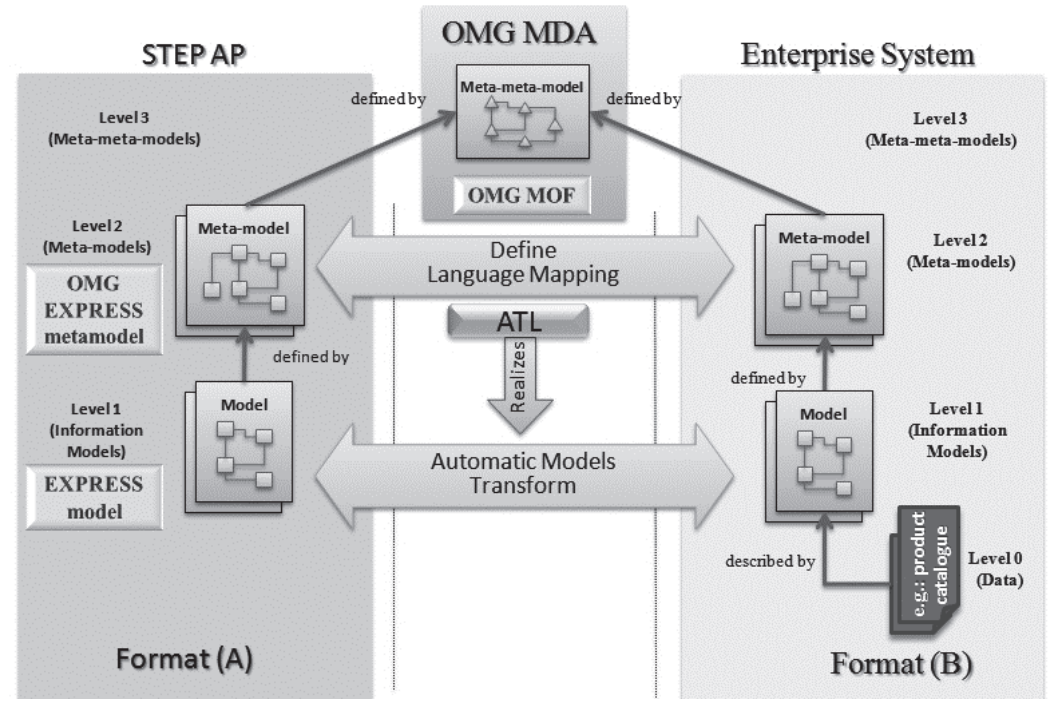

Fig. 5. MDA-based architecture for transformation of STEP models

The proposal to implement the transformation morphisms relies on a four level architecture that structures the relationships between meta-meta-models, meta-models, information models and data (see Fig. 5). The left-hand side of the figure represents the source STEP model, using the EXPRESS language as the information modelling language, whereas the right-hand side represents the organization's internal models. Using a common meta-metamodel, such as the OMG MOF5 it is possible to define the mappings among the meta-models at the level 2 of the MDA, which are the specifications of the modelling languages. With this, the transformation from any EXPRESS model to the desired format $B$ at the Level 1 can be realized, enabling the organization to implement with their preferred technologies, the parts of the $\mathrm{AP}$ it requires for a data exchange with other organizations (level 0), as explained in section 3 .

Given the context of MDA and MOF based meta-models transformation languages, the Atlas Transformation Language (ATL) is currently the largest user-base and has the most extensive available information such as reference guides, tutorials, programmers' forum, etc. It is the most used language to implement MDA based tools (Jouault \& Kurtev, 2007), having a specific Development Toolkit plug-in available in open source from the GMT Eclipse Modelling Project (EMP) ${ }^{6}$. Since the ATL can be applied to OMG meta-models (Grangel et al., 2008; Wimmer \& Seidl, 2009), automatic model transformations at the information model level are attained if the mapping of level 2 is written in ATL.

Consequently, using the proposed architecture, the language mapping procedure is a manual process, but the language transformations are always automatic and repeatable. Considering that the number of languages used for information modelling is not so high, it is an acceptable cost since each map is done only once for each language, independently of the number of times it is used / executed.

${ }^{5}$ OMG Meta Object Facility (MOF). www.omg.org/mof/

${ }^{6}$ http://www.eclipse.org/modeling/ 


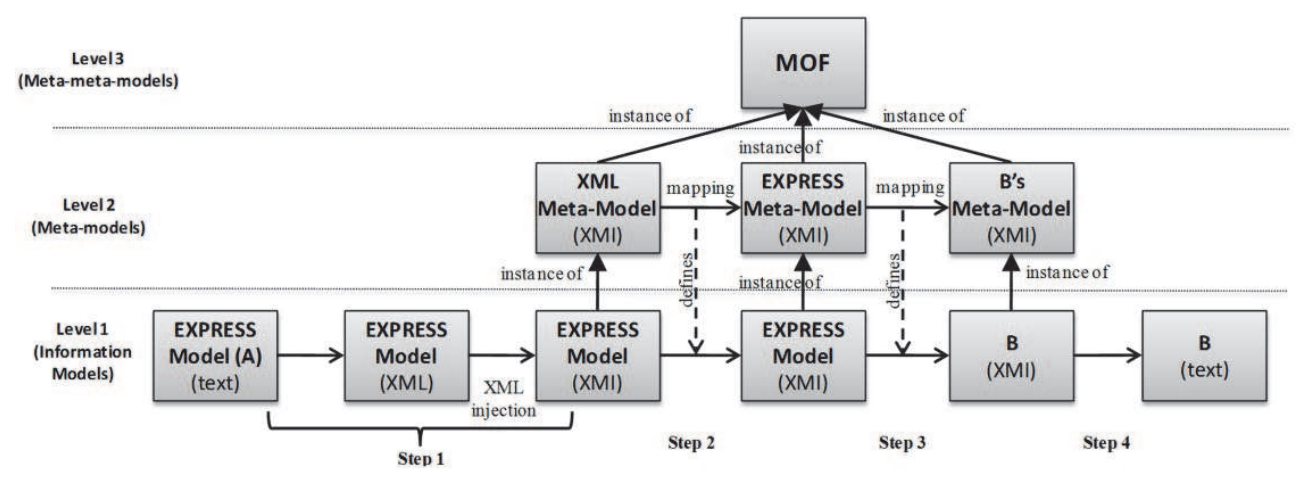

Fig. 6. ATL execution steps

Although ATL transformation input models can be represented in plain text like EXPRESS, it is preferable to use previously validated serialized XMI and EXPRESS meta-model (OMG, 2009) conforming models. Yet to achieve this, a number of steps have to be followed (Fig 6):

Step 0. (prerequisite) - All mappings from EXPRESS meta-model (format $A$ ) to the format $B$ meta-model need to be properly described in ATL;

Step 1. (from plain text to XML tagged file) - Eurostep EXPRESS Parser (EEP) ${ }^{7}$ is a command line parser which allows EXPRESS models (level 1) in text format to be validated against the published STEP standard, and can export an XML form of the validated models. The use of XML simplifies the process of representing the input models as instances of the EXPRESS meta-model, since XML can be natively injected by the ATL modelling tools, creating a valid XMI serialised instance;

Step 2. (EXPRESS meta-model injection) - the XML representation of the model has to be injected to the EXPRESS meta-model conforming model, and to accomplish that a transformation from the XML representation of the model must be executed, i.e. from the tags generated by the EEP to the ones used in the EXPRESS meta-model. This step can use specific ATL;

Step 3. (transformation) - After a successful EXPRESS injection, an instance of the EXPRESS meta-model, XMI serialized, is obtained. Using the EXPRESS mapping previously defined it is possible to execute the ATL rules automatically;

Step 4. (deserialize) -The result of step 3 provides a serialized XMI output according to B's meta-model. Therefore, in order to implement the STEP standard using language $B$, a model to text transformation must be written (ATL can also be used).

The number of steps might cause the impression of great complexity. However, that is not the case and those have only been here included to guide readers in their implementations. Also, in the future probably the steps will reduced to the fundamental step 3, with the further development of ATL frameworks.

\section{Semantic enrichment of standard-based product data}

Data can exist in multiple ways, independently of being usable or not. In the raw format, it does not have meaning in and of itself. However, information is data that has been given

${ }^{7}$ http://www.eurostep.com/global/solutions/download-software.aspx 
meaning by way of relational connection to a context (Breiter \& Light, 2004). Still, in information, this "meaning" can be useful for some, but not necessarily to all. It embodies the understanding of a relationship of some sort, possibly cause and effect, thus, people might "memorize" information (as less-aspiring students often do). Nevertheless, they would still be unable to understand it since they require a cognitive and analytical ability, i.e. knowledge (Bellinger et al., 2004).

Nonaka et al. (2001) define two kinds of knowledge: 1) Tacit, that people carry in their minds, which provides context for people, places, ideas, and experiences; 2) and Explicit, that has been or can be articulated, codified, and stored in certain media such as a STEP standard. In an ideal semantic based interoperability framework, both should be addressed and processable to achieve more advances stages of knowledge, such as understanding and wisdom (Bellinger et al., 2004; Jardim-Goncalves et al., 2009a or 2009b; Syed \& Shah, 2006). Since the explicit form has been handled by the industrial product data standards, the major research challenge nowadays is to gather the tacit knowledge domain stakeholders hold, in interpretable knowledge bases, thus transforming it to explicit knowledge stored in a structured organized way (Boudjlida \& Panetto, 2008). For reaching that purpose, literature suggests the usage of knowledge representation technologies such as dictionaries (domain, technical and natural language), glossaries, taxonomies, thesaurus and also ontologies, to build sustainable knowledge bases.

In the furniture industry, explicit knowledge is handled by the AP236 standard. However, as explained above, the use of the AP236 or any other STEP Application Protocol alone does not solve all the interoperability problems. Each supply chain stakeholder can have its own nomenclature and associated meaning for their business products. Therefore the information exchanged, in spite of sharing the same structure, still may not be understood by all business partners (Sarraipa et al., 2009a). Semantics interoperability is of major importance, and as such it is still to be solved, thus the authors, under the funStep initiative, are proposing the semantic enrichment of the furniture product data as a solution. The main objective is to organize the knowledge associated to the furniture products in order to enable a full understandable business messages and supply chain data exchange.

\subsection{Reference ontology for interoperability within enterprise networks}

An ontology produces a common language for sharing and reusing knowledge about phenomena in a particular domain. It is an agreed specification of how to describe all the concepts, (objects, people, processes, relationships, transactions, etc), of a particular domain of interest. Indeed, by defining concepts and relationships used to describe and represent an area of knowledge it provides a common understanding of the same, that before may have had different views and interpretations from the different practioners (Berners-Lee \& Fischetti, 1999; Guarino \& Oberle, 2009; Gruber, 1995). Following very simple modelling principles, it uses classes, properties and relationships to define a hierarchical view of the world (designated by taxonomy). An ontology is engineered by members of a domain which try to represent a reality as a set of agreed upon terms and logically-founded constraints on their use (Mika, 2005).

The development of ontologies has lately been widely adopted by companies. However, if all were to develop one of their own, all semantic issues would remain. This way, as a standard is needed to harmonize different information models existing in a supply chain, a reference ontology is needed to harmonize semantics. This reference ontology will be the 
knowledge front-end, enabling inter-enterprises terminology sharing (Jardim-Goncalves et al., 2009a or 2009b). Its building process is long and involves gathering human knowledge from many organizations.

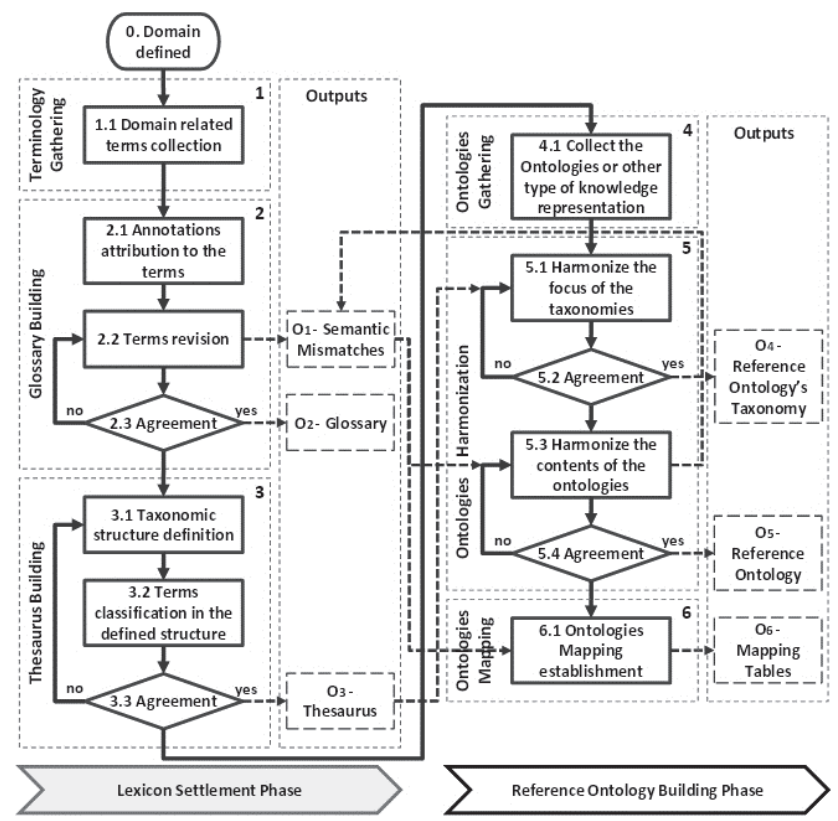

Fig. 7. MENTOR methodology (Sarraipa et al., 2010)

In this context, the development of an enterprise reference ontology can follow the MENTOR methodology (Fig 7). MENTOR - Methodology for Enterprise Reference Ontology Development, is a collaborative methodology developed for helping a group of people, or enterprises, sharing their knowledge with the other in the network, and provides several steps as semantic comparisons, basic lexicon establishment, ontology mappings and some other operations to build a domain's reference ontology. It aims to combine the knowledge described by different formalisms in a semantic interoperable way (Sarraipa et al., 2010).

The Lexicon Settlement, or Phase 1, represents the knowledge acquisition by getting a collection of terms and related definitions from all participants. This phase is divided into three steps: Terminology Gathering, Glossary Building, and Thesaurus Building. The first step is a very simple one, and represents the knowledge gathering from all participants in the collaborative network in a form of a list of terms. In the Glossary Building step, a glossary is built after a series of discussions about the terms that every participant contributed to the network on the previous step. These discussions are followed by a voting process, with all participants deciding which corresponding terms and definitions compose the glossary. Beyond the glossary, the semantic mismatches record is another output that results from this step. Finally, the last step of this phase is composed by a cycle where the knowledge engineers define a taxonomic structure with the glossary terms. If there is an agreement in both structure and classified terms, the thesaurus is defined. If not, the cycle 
starts again for another iteration. In this first phase, it could be valuable to have a multilanguage dictionary for situations where a common language is not shared by all participants.

The Reference Ontology Building, or Phase 2, is the phase where the reference ontology is built, and the semantic mappings between participant's ontologies and the reference ontology are established. This phase, just like the first phase, is divided into three steps: Ontologies Gathering, Ontologies Harmonization, and Ontologies mapping. The first step comprehends the acquisition of ontologies in the defined domain. In Ontologies Harmonization step, it is needed to proceed for taxonomic harmonization and contents harmonization. First, a discussion and voting process about the reference ontology structure takes place where the common classes are defined by unanimity. This process of discussing and voting is then repeated for the contents harmonization. The final step of this phase, the Ontology Mapping, attempts to relate the vocabulary of two ontologies that share the same domain. In this case, the idea is to establish mappings between each participant's ontology and the reference ontology defined on the previous step (Sarraipa et al., 2010).

\subsection{The funStep knowledge representation elements}

As evidenced in Jardim-Goncalves et al. (2010) funStep endeavours to gather the tacit knowledge that furniture supply chain stakeholders hold into machine interpretable knowledge bases. For reaching that objective, the authors are proposing to integrate the funStep standard (AP236) with the reference funStep Lexicon, which embodies the reference concepts and semantics, and with a funStep reference ontology, which embraces product classification to its related properties. This leads to the knowledge architecture definition where the integrated knowledge is composed by four Knowledge Representation Elements (KREs): the funStep Ontology; the funStep Thesaurus; the funStep Dictionary, and the funStep AP236 (Fig 8).

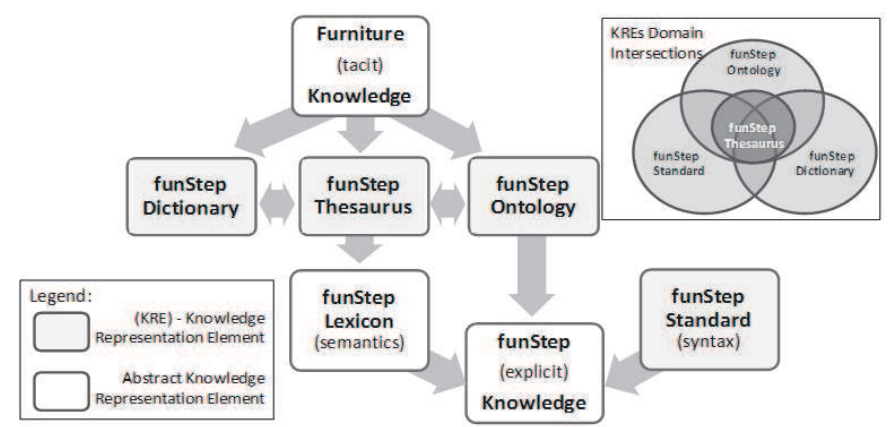

Fig. 8. funStep knowledge architecture (Sarraipa et al., 2009a)

For a good explicit knowledge representation, it is needed to have significant input from the tacit source (i.e., domain experts). Thus, such characteristic requires a knowledge architecture enabling the management of the evolution between the KREs:

- The evolution of the first three KREs leads to the funStep Lexicon establishment which is an abstract KRE because that it is composed by thesaurus contents;

- On the other hand, the funStep explicit knowledge KRE is another abstract KRE since it is composed by the addition of the funStep Lexicon with the ontology and the standard 
itself. The funStep explicit knowledge represents all the furniture machine interpretable knowledge where the funStep dictionary and the thesaurus are supporting KREs to the funStep Lexicon establishment and maintenance.

\subsection{1 funStep dictionary}

A domain dictionary has been found to be one of the most useful tools for a domain analysis. The use of a dictionary reduces miscommunication by providing users an easy access to information about terms and abbreviations that are completely new to them. The funStep dictionary supports a multilingual collection of terms, thus enabling a correct coordination between international partners. Also, the terms are associated to other related terms.

\subsection{2 funStep ontology}

The funStep ontology is being developed thanks to some of the funStep-driven research projects such as SMART-fm. It started by being a set of reference data for furniture product classification in electronic commerce, but nowadays, it is being evolved according to the MENTOR methodology and gifted with functionalities such as semantic comparisons, basic lexicon establishment, harmonization among other ontologies, etc.

\subsection{3 funStep thesaurus}

The basic lexicon establishment is reached by the development of a thesaurus on the domain. It is composed by a set of domain reference terms and concepts, clustered on the basis of their similarity, and organized by means of semantic relationships (e.g., equivalence, subsumption, generalization, disjunction) to enable a better retrieval process of semantically related terms (Missikoff et al. 2004). A thesaurus can serve as a controlled vocabulary where terms are constrained to its domain-specific meanings, avoiding the problem of ambiguity (Gatlin, 2005). The funStep thesaurus envisages a multi-national scope of vocabulary, where terms with the same meaning coexist in multiple languages. Therefore, the thesaurus can be seen as a collection of parts of the dictionary, ontology and AP236 as illustrated on the top right part of Fig 8 .

\subsubsection{Semantic modules of the funStep AP236 standard}

As described earlier in this chapter (section 3.1) the AP236 standard has been developed following a modular approach to optimize reutilization and harmonization with the other STEP application protocols. In fact, some of these common structures are the modules that enable a direct link with knowledge representation elements to semantically enrich standard data. The set of modules of funStep standard (conformance options) that enable product classification and multilinguism are examples of relevance for semantic enrichment.

\section{External Classification}

Each company in a supply chain has its own product nomenclature and structure. This is easily verified not only in the way catalogues are arranged, but also in the different designations companies use for the same concept. However, for an improved business, networks of organizations may define, or use shared reference ontologies or thesaurus, instead of legacy taxonomies. In this case, when exchanging product information, they should classify their products using that reference nomenclature. AP236 provides a mechanism for that, i.e. the external classification conformance option. 


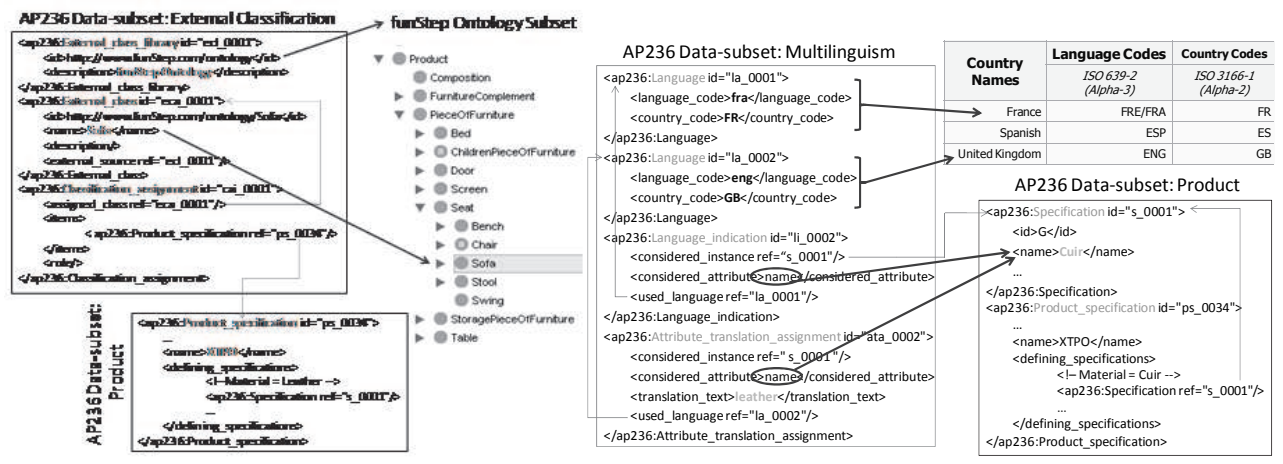

Fig. 9. AP236 semantic link examples

External classification enables a direct link between the context and the classes of products. Nevertheless, the mentioned link uses meanings that are expressed in libraries physically described in remote locations. The left side of Fig 9 illustrates how external classification works: the product manufacturer links with the funStep reference ontology, using the AP236 entities: "external_class" and "external_class_library", to identity the externally defined concepts, and "classification_assignment" to establish the link with the product in the catalogue.

\section{Multilinguism}

For a better internationalization of the market, companies must be able to send their products and associated information in several languages, especially in the language the receiver company speaks. The multilinguism conformance option of AP236 addresses such need, so that any organization could receive data in their native language independently of where it was introduced or manufactured.

Multilinguism allows the translation of the attributes of AP236 entities in any number of languages. In the right side of Fig 9, it is possible to notice that the AP236 entity "language" is used to indicate the reference language. The entity "language_indication" points to the attribute that one wants to translate, and the "attribute_translation_assignment" specifies the translation itself. In the example, it is the value of the attribute "name" that is being translated from the French "cuir" to the English "leather".

\subsection{The funStep knowledge framework}

Semantics is the study of language units meaning and their combinations. Therefore, semantic enrichment is the act or process of adding specific meaning elements to some knowledge representation structure in a domain, to help on the information clarification. This way, the funStep standard semantic enrichment is characterized as being performed at two basic levels: Terminological annotation, by using the terms identified in the Lexicon (Thesaurus); and semantic annotation, by using concepts and expressions drawn from the reference ontology.

Both levels are conducted through a knowledge framework as illustrated on Fig 10, which is based on the KREs identified before. It is built up on web services technology enabling interoperable open services over the internet between the funStep knowledge client systems and the funStep knowledge server. This architecture is composed by three parts: 


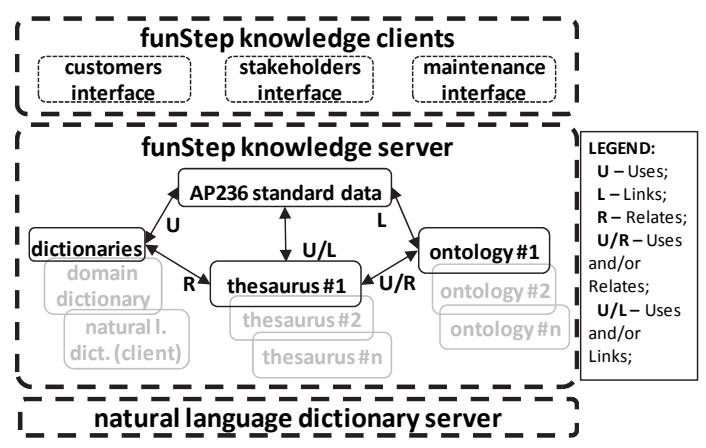

Fig. 10. funStep knowledge framework

- $\quad$ The natural language dictionary (NLD) server that complements the domain dictionary in the translation procedure of natural language information used within the AP236 multilingual data. For instance, let's imagine a request for quotation for a special request of a 2,5 meters long bed, sent by the e-marketplace of section 3.3 to a Portuguese manufacturer. He would need to translate something like "Bed 1452 with a length of $2,5 \mathrm{~m}$ " and would use the domain dictionary for the translation of "bed" and possibly "lenght", but the rest needs to be handled by a NLD.

- The funStep knowledge server which is composed by the four funStep KREs described in the previous section, whose relationships enable the semantic enrichment of the standards data;

- The funStep knowledge clients that can be administrators, customers, or stakeholders. The role of the first is mainly related to KRE's evolution and maintenance, while the second are provided with functionalities that go beyond simple product search, namely enabling software developers with skills to develop enhanced intelligent products search engines based on knowledge reasoning. Finally, stakeholder interfaces are related to standard semantic enrichment itself.

\section{Conclusions}

To solve interoperability problems in the furniture supply chain, consisting mostly of SMEs with heterogeneous needs, funStep has created an ISO standard which defines a formal structure for catalogue and product data under industrial domains of the furniture sector.

Due to the modularization properties of STEP it is possible to establish direct cross-sectorial links with other ISO standards. Among them are the automotive, aircraft, ship-building, building \& construction and other relevant sectors to the furniture segment, e.g. many furniture manufacturers and designers act as suppliers sub-contracted by other sectors, like automotive (refurbishment), ship-building (luxury Yates) or building \& construction (woodmade houses).

However, the main benefit of adopting the ISO funStep standard is the increased efficiency that results from sharing data between different ICT systems seamlessly bringing additional benefits without the need for re-enter information. Thus, there is a reduction of human errors and end-to-end transaction time (lead-time). Using standard compliant systems means that, component or products suppliers can provide full technical information about their products to the retailer or e-marketplace, who in turn, can publish catalogues, operate 
e-commerce systems, manage stock control systems or supply data to interior designers in an interoperable manner, all without the need to enter any data more than once. Customer orders placed with retailers can be communicated back up the supply chain immediately, enabling components, materials and manufacturing resources to be allocated at the earliest opportunity. Furthermore, it enables to combine catalogue data from several sources in a single retail management system by importing component specifications from multiple suppliers to a furniture design or manufacturing system.

Nevertheless, due to the complexity associated with the implementation of standards, especially STEP standards, the SMEs require a push. Mechanisms to facilitate and accelerate the adoption task and simultaneously minimizing the costs are required and are proposed in this chapter. Indeed, an example of which steps an e-marketplace should take to implement AP236 and become rapidly integrated with more manufactures has been demonstrated and used successfully during the INNOVAFUN project. Also, due to being an unfamiliar technology and lacking support from open or free solutions, in that situation the company decided to go for a XML-based implementation instead of using the native STEP formats.

Information and communications technology combined with the use of open-standards can be a very powerful tool to improve enterprise competitiveness via a wider adoption of STEP APs. However, with so many different modelling and implementation standards being used, interoperability problems arises when the chosen product model is described using one particular technology (e.g. EXPRESS) and is required to be integrated with systems that use totally different technologies (e.g. XML). Being ISO10303 STEP acknowledged, by most of the major industrial companies in the world within different sectors, as one of the most important family of standards for exchange of product data under the manufacturing domain, it would be expected to be broadly used. However, that is not so, especially on SME-based environments because the technology is unfamiliar to most application developers.

Based on that requirement, MDA technology can be used to enable automation of model morphisms, and therefore, translation at the information model and data levels (level 1 and 0 of MDA). The first translation (level 1) is used exclusively to obtain language independency, providing a neutral ground for implementations and to define the necessary mappings to enable supply chain systems interoperability (level 0), which is realized by the real link between two enterprises. The proposed MDA-based architecture enables gradual and sustained system interoperability, since allows incremental AP236 implementations (using the conformance options and classes) without the need to rewrite the full system from scratch. Once the mappings are defined, the standard modelling language is no longer an issue, and the same MDA principle can be applied to the actual data to be exchanged, i.e. if its internal system already has the capabilities implemented but they are not integrated with the standard, only additional mappings need to be defined to transform internal data into AP236 format. The results presented in this part of the work have been applied and validated in several European/International industrial research projects such as IMS SMART-fm, Athena-IP, and InterOp NoE.

Finally, apart from being a technical issue, interoperability challenges also appear in the enterprises at organizational and semantic level, underlying the need for patterns and solutions that support the seamless cooperation among ICT systems, information and knowledge, organizational structures and people (Tursi, et al 2009, Jardim-Goncalves et al., 2009; Jardim-Goncalves \& Grilo, 2009a \& 2009b). Indeed, Schrage (1990), emphasizes that the 
issue in collaboration "isn't communication or teamwork, it's the creation of value". By this definition, it is possible to conclude that he was looking at collaboration from a perspective of people and not systems. Therefore, if instead of just looking at the software systems perspective, one could generalize to the everyday's experience, it is possible to conclude that even though people have different cultural backgrounds or education, they can communicate (at least at basic level) if they speak the same language. The authors use this premise and apply it to the systems inter-enterprise level proposing a knowledge framework for semantic enrichment of supply chain data. The proposed funStep knowledge framework provides enterprise and manufacturing systems a semantically seamless communication with other stakeholders up and down the supply chain.

The authors, under the funStep initiative which is continuing the activities begun by the IMS SMART-fm project, propose the semantic enrichment of standardized product data as a solution for making interoperable intelligent manufacturing systems a reality. They endeavour to gather the tacit knowledge that furniture domain stakeholder's hold into machine interpretable knowledge bases, which should be stored in a structured organized way, where syntax and lexical semantics are integrated as explicit knowledge. This allows enterprises to keep their internal terminologies and classification systems, and still remain interoperable with their business partners, through the usage of knowledge mapping procedures. Together, the domain dictionary, the thesaurus, the reference ontology and the AP236 standard itself act as explicit knowledge repository and reference lexicon for the application domain.

In the past, the funStep framework was able to deliver two levels of product data exchange interoperability compliance: (level 1) - not funStep compliant - where the messages exchanged are following any kind of format other than the AP236 standard; (level 2) - funStep compliant - where, the exchanged messages were compliant with the AP236 standard. From the research results presented in this chapter, the funStep Knowledge framework is extended adding semantics compliance to it, i.e. (level 3) - funStep knowledge compliant. With level 3 compliance, systems communications would be syntactically compliant with the AP236 standard and as well semantically compliant with the reference funStep knowledge.

Besides what has been here detailed, funStep provides a permanent support to the furniture supply chain with a set of services available to the end user in the form of: a) Software Services; b) Training Services; c) Validation Services and d) Consultancy Services (INNOVAFUN, 2008). The services have the objective of assisting on the funStep standard comprehension, implementation process, and also on development and design of new business practices on SMEs. They offer new opportusnities for innovation and content management, while also achieving lower costs and more rapid deployment

\subsection{Future work}

Manufacturing and retailing systems are becoming more and more complex and dynamic. They need to be constantly adapting to new market and customer requirements who demand a faster and better quality service. Even standards need to be adjusted from time to time. This behaviour is reflected in a constant fluctuation and evolution of business networks and system models, which makes interoperability difficult to maintain.

The open research questions raised in the introduction are not completely answered, and despite of the importance of enterprise interoperability (EI) in the global economy, there is not yet an established scientific base for EI. Due to this fact, situations such as loss of interoperability have a great impact on the enterprise turnover. Indeed, it is of paramount 
importance to identify an EI science base that embodies lessons learnt from the neighbouring domains such as complexity or services science. The aim in the future is to formalise interoperability problems and solutions such as the ones here discussed, ultimately guaranteeing reusability and repeatability.

The authors intend to address this non-linear problem in future research involving feedback, monitoring and prognosis mechanisms as part of the business network solutions. With these, they intend to include dynamism in the morphisms maintenance among systems, thus allowing automatic readjustments in the information flows without the need to reprogram the full systems. In this line, the ENSEMBLE FP7 project (http://www.ensemble-csa.eu) is already providing the framework to validate such results and considerations, working within the Future Internet Enterprise Systems (FInES) community to develop and implement a systematic approach to the establishment of EI as a science.

\section{Acknowledgement}

The authors would like to thank all the organizations supporting the international projects that resulted in the development of the platform presented in this paper. Namely, the European Commission that funded the IMS SMART-fm and the INNOVAFUN projects; their partners that somehow contributed for the presentation of this work; CEN/ISSS and ISO TC184/SC4 for the effort in developing industrial standards and binding guidelines, and the SMART-fm inter-regional consortium for providing a global validation of the work presented. Also they appreciate the assistance provided by the EC Future Internet Enterprise Systems (FInES) cluster, namely projects ATHENA IP, INTEROP NOE, and FP7 ENSEMBLE CSA for their contributions during the development of various ideas and concepts presented in this chapter.

\section{References}

Agostinho, C., Delgado, M., Steiger-Garcao, A., Jardim-Goncalves, R. (2006) Enabling adoption of standard STEP through the use of popular technologies Space. 13th ISPE Int. Conference on Concurrent Engineering: Research and Applications, France.

Agostinho, C. and Sarraipa, J. and D'Antonio, F. and Jardim-Goncalves, R. (2007). Enhancing STEP-based Interoperabity Using Model Morphisms. 3rd Int Conference Interoperability for Enterprise Software and Applications (I-ESA07), Portugal.

Agostinho, C. and Dutra, M. and Jardim-Goncalves, R. and Ghodous, P. and Steiger-Garcao, A. (2007). EXPRESS to OWL morphism: making possible to enrich ISO10303 Modules. 14th ISPE International Conference on Concurrent Engineering (CE2007), 16-20 Jul 2007, São José dos Campos, Brazil

Agostinho, C., and Almeida, B. and Nuñez-Ariño, MJ. and Jardim-Goncalves, R. (2009). Interoperability and Standards: The Way for Innovative Design in Networked Working Environments. 18th CIRP DESIGN Conference - Competitive Design (CIRP2009), Cranfield, UK, March 2009

Agostinho, C., Sarraipa, J., Goncalves, D., Jardim-Goncalves, R. (2011). Tuple-based semantic and structural mapping for a sustainable interoperability. In proc. of $2^{\text {nd }}$ Doctoral 
Conference on Computing, Electrical and Industrial Systems (DOCEIS'11), Portugal.

Bellinger, G., Castro, D., Mills, A.(2004). Data, Information, Knowledge, and Wisdom [online]. [2010] Available from: www.systems-thinking.org/dikw/dikw.htm.

Berners-Lee, T., Fischetti, M. (1999): Weaving the Web: The Original Design and Ultimate Destiny of the World Wide Web by Its Inventor. HarperOne, San Francisco

Boudjlida Nacer; Panetto Hervé (2008). Annotation of enterprise models for interoperability purposes. IEEE International Workshop on Advanced Information Systems for Enterprises, IWAISE'2008, April 2008, Constantine, Algeria. pp. 11-17

Breiter, A. and Light, D. (2004). Decision Support Systems in Schools - from Data Collection to Decision Making. In: AMCIS 2004 -Tenth Americas Conference on Information Systems, August 2004, New York, USA

Brunnermeier, S.B. \& Martin, S.A. (1999) Interoperability cost analysis of the US automotive supply chain (NIST 99-1 Planning Report), Gaithersburg, MD, USA.

European Commission (EC), DG Enterprise \& Industry (2008). ICT and e-Business Impact in the Furniture Industry: A Sectoral e-Business Watch study by Databank; Impact Study No. 3/2008.

European Comission (EC), (2008). Enterprise Interoperability Research Roadmap (version 5.0). Future Internet Enterprise Systems Cluster (FInES).

European Comission (EC), (2010). Future Internet Enterprise Systems Research Roadmap (version 3.0). Future Internet Enterprise Systems Cluster (FInES).

Fan, I.-S., Filos, E. (1999) Concurrent Engineering: Esprit-supported R\&D Projects in a World-wide Context, in: Proceedings of ICE'99, International Conference on Concurrent Enterprising, The Hague, The Netherlands, 15-17 March 1999, Nottingham: University of Nottingham, ISBN 0 9519759 86, 177-189.

Farinha, F.; Jardim-Goncalves, R.; Steiger-Garcao, A. (2007) Integration of cooperative production and distributed design in AEC. International Journal Advances in Engineering Software, Special issue, 2007, ISSN: 0965-9978, ELSEVIER.

Feeney, A. (2002) The STEP Modular Architecture, Journal for Computing and Information Science in Engineering, Volume 2, Issue 2, 132

Franconi, E. (2004): Using Ontologies. IEEE Intelligent Systems. Vol.19, No.1, pp. 76--79

Frankel D. S., (2003), Model Driven Architecture - Applying MDA to Enterprise Computing, OMG Press

Gaston, C. and R.A. Kozak (2001). "Forest Products Annual Market Review, 2000 - 2001". Chapter 6: Sawn Softwood - Consumption, Production and Trade. Published by the Economic Commission of Europe and the Food and Agriculture Organization of the United Nations. United Nations Publications, ISSN 0259-4323 (Timber Bulletin - Volume 54 (2001), No. 3. p. 57 - 72

Gatlin, K.A. (2005). Enhancing Cross-Language Retrieval of Comparable Corpora Through Thesaurus-Based Translation and Citation Indexing. In UNC SILS Master's Papers. School of Information and Library Science

Grangel R., Bigand M., Bourey J.P. (2008) A UML Profile as Support for Transformation of Business Process Models at Enterprise Level. In: MDISIS 2008

Gruber, T. R. (1995). Toward principles for the design of ontologies used for knowledge sharing. International Journal of Human-Computer Studies, 43(5-6), 907-928 
Guarino, N; Oberle, D.; (2009). What is an Ontology?. In S. Staab and R. Studer (eds.), Handbook on Ontologies (2nd edition), Int. Handbooks on Information Systems.

Gupta, A.; Maranas, C. D. (2003). Managing demand uncertainty in supply chain planning. In: Computers and Chemical Engineering 27 1219/1227

INNOVAFUN - EC INNOVA Project No.: 031139, (2007), Deliverable 1.2, Use cases and action plan for standard adoption and implementation

INNOVAFUN - EC INNOVA No.: 031139, (2008), Deliverable 2.1, Services for funStep standard adoption and design of new business practices; http:/ / gris-public.uninova.pt:8080/funStepServices/

INTEROP NoE (2005). Deliverable MoMo.2 - TG MoMo Roadmap. InterOP

ISO TC184/SC4 (2002). Industrial automation systems and integration-Product data representation and exchange-Part 21: Implementation methods: Clear text encoding of the exchange structure

ISO TC184/SC4 (2004). Product data representation and exchange-Part 11: Description methods: The EXPRESS language reference manual

ISO TC184/SC4 (2005). Industrial automation systems and integration - Product data representation and exchange - Part 25: Implementation methods: EXPRESS to XMI binding.

ISO TC184/SC4 (2006). Industrial automation systems and integration -- Product data representation and exchange -- Part 236: Application protocol: Furniture catalog and interior design, Dec 2006

ISO TC184/SC4 (2007). Industrial automation systems and integration - Product data representation and exchange - Part 28: Implementation methods: XML representations of EXPRESS schemas and data, using XML schemas.

Jardim-Gonçalves R, Cabrita, RO, Steiger-Garção A, (2005), The emerging ISO10303 Modular Architecture: In search of an agile platform for adoption by SMEs, International Journal of IT Standards and Standardization Research (IJITSR), Vol. 3 (2). pp. 82-95, ISSN 1539-3062.

Jardim-Goncalves, R., Panetto, R., Nuñez, M.J., Steiger-Garcao, A., (2007), SMART-fm: setting interoperability in SME-based industrial environments, ADVANCED MANUFACTURING: AN ICT \& SYSTEMS PERSPECTIVE book, Taylor and Francis Group, London, UK.

Jardim-Goncalves, R.; Figay, N; Steiger-Garcao, A (2006b); Enabling interoperability of STEP Application Protocols at meta-data and knowledge level. International Journal of Technology Management (IJTM), 2006

Jardim-Goncalves, R.; Grilo, A; Steiger-Garcao, A (2006c). Challenging the Interoperability in the Construction Industry with MDA and SoA. Computers in Industry, Vol. 57, Issues 8-9, 2006

Jardim-Goncalves, R.; Grilo, A; Steiger-Garcao, A; (2007). Developing interoperability in mass customization information systems, in book Mass Customization Information Systems in Business, ISBN-10: 1599040395, 2007.

Jardim-Goncalves, R. and Agostinho, C. and Maló, P. and Steiger-Garcao, A. (2007). Harmonizing technologies in conceptual models representation. International Journal of Product Lifecycle Management (IJPLM), Vol. 2 (2). pp. 187-205. ISSN 1743-5129 
Jardim-Goncalves, R. and Nunez, MJ. and Roca-Togores, A. and Steiger-Garcao, A. (2008) Managing engineering and technology with better interoperability in smart organizations. In: PICMET'08 - 2008 Portland International Conference on Management of Engineering \& Technology, 27-31 Jul 2008, Cape Town, South Africa.

Jardim-Goncalves, R.; Sarraipa, J. Agostinho, C. and Panetto, H. (2011): Knowledge framework for intelligent manufacturing systems. in Journal of Intelligent Manufacturing. DOI 10.1007/s10845-009-0332-4; Published online: 22 October 2009

Jardim-Goncalves R, Grilo A (2009). Putting the building and construction industry in the Single European Information Space. In: J. Automation in Construction, AUTOCON

Jardim-Goncalves R, Grilo A (2009). Value proposition of interoperability on BIM and collaborative working environments. In: J. Automation in Construction AUTOCON

Jardim-Goncalves, R., Agostinho, C. and Steiger-Garcao, A. (2010); Sustainable Systems' Interoperability: A reference model for seamless networked business. In the Proceedings of 2010 IEEE International Conference on Systems, Man, and Cybernetics (SMC 2010), Istanbul, Turkey

Jouault F, Kurtev I, (2007) "On the interoperability of model-to-model transformation languages", Science of Computer Programming, no. 68, pp. 114-137.

Kalfoglou Y., Schorlemmer M., (2003) Ontology mapping: the state of the art. The Knowledge Engineering Review, Volume 18, Issue 1, ISSN:0269-8889.

Lubell, J.; Peak, R. S.; Srinivasan, V; Waterbury S. C. (2004); “STEP, XML, AND UML: COMPLEMENTARY TECHNOLOGIES"; ASME 2004 Design Engineering Technical Conferences and Computers and Information in Engineering Conference (DETC 2004); Salt Lake City, Utah USA

Mika, P. (2005). Ontologies Are Us: A unified model of social networks and semantics. International Semantic Web Conference, Vol. 3729 (November 2005), pp. 522-536

Missikoff M., Boudjlida N., Lenzerini M., Jeusfeld M., Johannesson P., et al. (2004). D8.1 State of the art and state of the practice including initial possible research orientations, Interoperability Research for Networked Enterprises Applications and Software Network of Excellence, $n^{\circ}$ IST 508-011, November 2004

Molina, A., Rodriguez, C. A., Ahuett, H., Cortés, J. A., Ramírez, M., Jiménez, G. and Martinez, S.(2005). Next generation manufacturing systems: key research issues in developing and integrating reconfigurable and intelligent machines. In: International Journal of Computer Integrated Manufacturing, 18:7,525 - 536

Nonaka, I., Konno, N., Toyama, R. (2001). Emergence of “Ba”. In Nonaka, I. and Nishiguchi, T., Knowledge Emergence: Social, Technical, and Evolutionary Dimensions of Knowledge Creation, pp. 13 - 29, Oxford University Press US

Object Management Group (OMG). (2009). Reference Metamodel for the EXPRESS Information Modeling Language, Version 1.0 - Beta 3. November 2009

Panetto, H., Jardim-Gonçalves, R., Pereira, C. (2006). Special issue on E-Manufacturing and Web-Based Technology for Intelligent Manufacturing and Networked Enterprise. Journal of Intelligent Manufacturing, Vol. 17 (6). pp. 639-698.

Roca de Togores A, Agostinho C. (2008). Handbook: Improving interoperability in furniture SME's using funStep standard-based solutions. 2008, INNOVAFUN - EC INNOVA Project No.: 031139, Deliverable 2.4. 
Rudberg, M.; Klingenberg, N.; Kronhamn, K. (2002). Collaborative supply chain planning using electronic marketplaces. In: Integrated Manufacturing Systems Journal; vol. 13; N. 8; pp: 596-610; MCB UP Ltd; ISSN: 0957-6061.

Sarraipa, J., Agostinho, C., Panetto, H., Jardim-Goncalves, R. (2009): Semantic Enrichment of Standard-based Electronic Catalogues. In Proceedings of 13th IFAC Symposium on Information Control Problems in Manufacturing (INCOM'09). Moscow, Russia IFAC PapersOnLine

Sarraipa, J; Vieira, H.; Agostinho, C.; Jardim-Goncalves, R. (2009): Methodology for Seamless Supply Chain Planning. In Proceedings of 1st International Conference on Software, Services \& Semantic Technologies Sofia, Bulgaria

Sarraipa, J., Jardim-Goncalves, RJ., Steiger-Garcao, A., (2010). MENTOR: an enabler for interoperable intelligent systems. Int. Journal of General Systems, v 39(5), pp.557573

Schrage M. Shared Minds. (1990), Random House, New York, p.140

Subrahmanian, E., Rachuri, S., Fenves, S.J., Foufou. S., and Sriram, S.D. (2005), 'Product lifecycle management support: a challenge in supporting product design and manufacturing in a networked economy', Int. J. Product Lifecycle Management, vol. 1, No.1, pp.4-25

Syed, A., Shah,A. (2006). Data, Information, Knowledge, Wisdom: A Doubly Linked Chain?. Proceedings of the 101 ${ }^{\text {st }}$ International Conference on Information and Knowledge Engineering

Tursi Angela; Panetto Hervé; Morel Gérard; Dassisti Michele (2009). Ontological approach for product-centric information system interoperability in networked manufacturing enterprises. Annual Reviews in Control, 2009, 33 (2), pp. 238-245

White, William J, Ph.D., O'Connor, Alan C and Rowe, Brent R (2004). Economic Impact of Inadequate Infrastructure for Supply Chain Integration. RTI International. s.l. : National Institute of Standards and Technology (NIST).

Wimmer M, Seidl M. Model Transformation with ATL (2009). In: 1st International Workshop, France, July 8-9, MtATL 


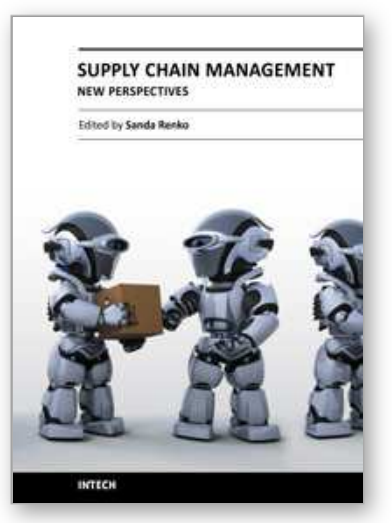

\author{
Supply Chain Management - New Perspectives \\ Edited by Prof. Sanda Renko
}

ISBN 978-953-307-633-1

Hard cover, 770 pages

Publisher InTech

Published online 29, August, 2011

Published in print edition August, 2011

Over the past few decades the rapid spread of information and knowledge, the increasing expectations of customers and stakeholders, intensified competition, and searching for superior performance and low costs at the same time have made supply chain a critical management area. Since supply chain is the network of organizations that are involved in moving materials, documents and information through on their journey from initial suppliers to final customers, it encompasses a number of key flows: physical flow of materials, flows of information, and tangible and intangible resources which enable supply chain members to operate effectively. This book gives an up-to-date view of supply chain, emphasizing current trends and developments in the area of supply chain management.

\title{
How to reference
}

In order to correctly reference this scholarly work, feel free to copy and paste the following:

Ricardo Jardim-Goncalves, Carlos Agostinho, João Sarraipa, Amparo Roca de Togores, Maria José Nuñez and Hervé Panetto (2011). Standards Framework for Intelligent Manufacturing Systems Supply Chain, Supply Chain Management - New Perspectives, Prof. Sanda Renko (Ed.), ISBN: 978-953-307-633-1, InTech, Available from: http://www.intechopen.com/books/supply-chain-management-new-perspectives/standardsframework-for-intelligent-manufacturing-systems-supply-chain

\section{INTECH}

open science | open minds

\author{
InTech Europe \\ University Campus STeP Ri \\ Slavka Krautzeka 83/A \\ 51000 Rijeka, Croatia \\ Phone: +385 (51) 770447 \\ Fax: +385 (51) 686166 \\ www.intechopen.com
}

\author{
InTech China \\ Unit 405, Office Block, Hotel Equatorial Shanghai \\ No.65, Yan An Road (West), Shanghai, 200040, China \\ 中国上海市延安西路65号上海国际贵都大饭店办公楼 405 单元 \\ Phone: +86-21-62489820 \\ Fax: +86-21-62489821
}


(C) 2011 The Author(s). Licensee IntechOpen. This chapter is distributed under the terms of the Creative Commons Attribution-NonCommercialShareAlike-3.0 License, which permits use, distribution and reproduction for non-commercial purposes, provided the original is properly cited and derivative works building on this content are distributed under the same license. 